\title{
DISCURSO PRONUNCIADO POR OCASIÃO DA SOLENIDADE DE POSSE DO PROFESSOR LUIZ CARLOS DE AZEVEDO COMO TITULAR DO DEPARTAMENTO DE DIREITO CIVIL
}

No momento em que vamos completando quase três décadas de magistério nesta nobre Casa de ensino do Direito, e quando nos acercamos da jubilação pela idade; depois de não sei quantas e tantas aulas de Direito Processual Civil, forçoso é reconhecer que a vida outra coisa não é, também, do que um processo, pois como este e de igual feição, desenvolve-se por etapas, num contínuo e ininterrupto caminhar, caminhar para a frente, empós de um objetivo e de uma finalidade.

Processo de conhecimento, cujo na infância e juventude se adquire, na ânsia e busca para descerrar um mundo novo, que a cada passo se descobre, oferecendo surpresas, perplexidades, desafios, vitórias, ultrapassagens. Armados desta bagagem que o conhecimento proporcionou, partimos para o processo de execução, construindo idéias, realizando-as, atravessando e superando obstáculos para o fim de transmitir toda a experiência consolidada no estádio anterior. E nem se descura, outrossim, do processo cautelar, no sentido de que este visa assegurar e preservar os resultados obtidos e conquistados.

Não foi outro e nem o é, ainda, o nosso intuito e empenho, desde que aqui ingressamos, primeiro, nos bancos acadêmicos, no início dos anos 50; a seguir, nos anos 70, complementando com aulas práticas, aos sábados, o programa ministrado pela professora Ada Pelegrini Grinover pelo professor Antonio Carlos de raújo Cintra; nesse mesmo período, como pós-graduando, sob a orientação do professor Moacyr Lobo da Costa; continuando o magistério, na assistência deste notável mestre, até que fomos honrados em substituí-lo na regência das aulas do último ano do curso de graduação, já nos anos 80; persistindo esta trajetória no processo civil, como também na História do Processo Civil Romano, Canônico e Lusitano, juntamente com o professor José Rogério Cruz e Tucci, dando seqüência ao curso criado pelo professor Moacyr Lobo da Costa, no âmbito da pós-graduação; e, finalmente, nos anos 90 , na História do Direito, a qual voltara a integrar o currículo por iniciativa e mérito do professor Antonio Junqueira de Azevedo.

Havia esta cadeira feito parte do curso de ciências jurídicas durante o século XIX, tendo como responsáveis renomados professores da época: no Recife, o professor Isidoro Martins Junior, autor de conhecido compêndio, a "História do Direito Nacional" o qual, por sua importância, mereceu nova publicação em 1979; em São Paulo, o professor Aureliano de Souza Coutinho, que em seu discurso de posse, nesta casa, ressaltava o valor da História do Direito como fator preponderante para a 


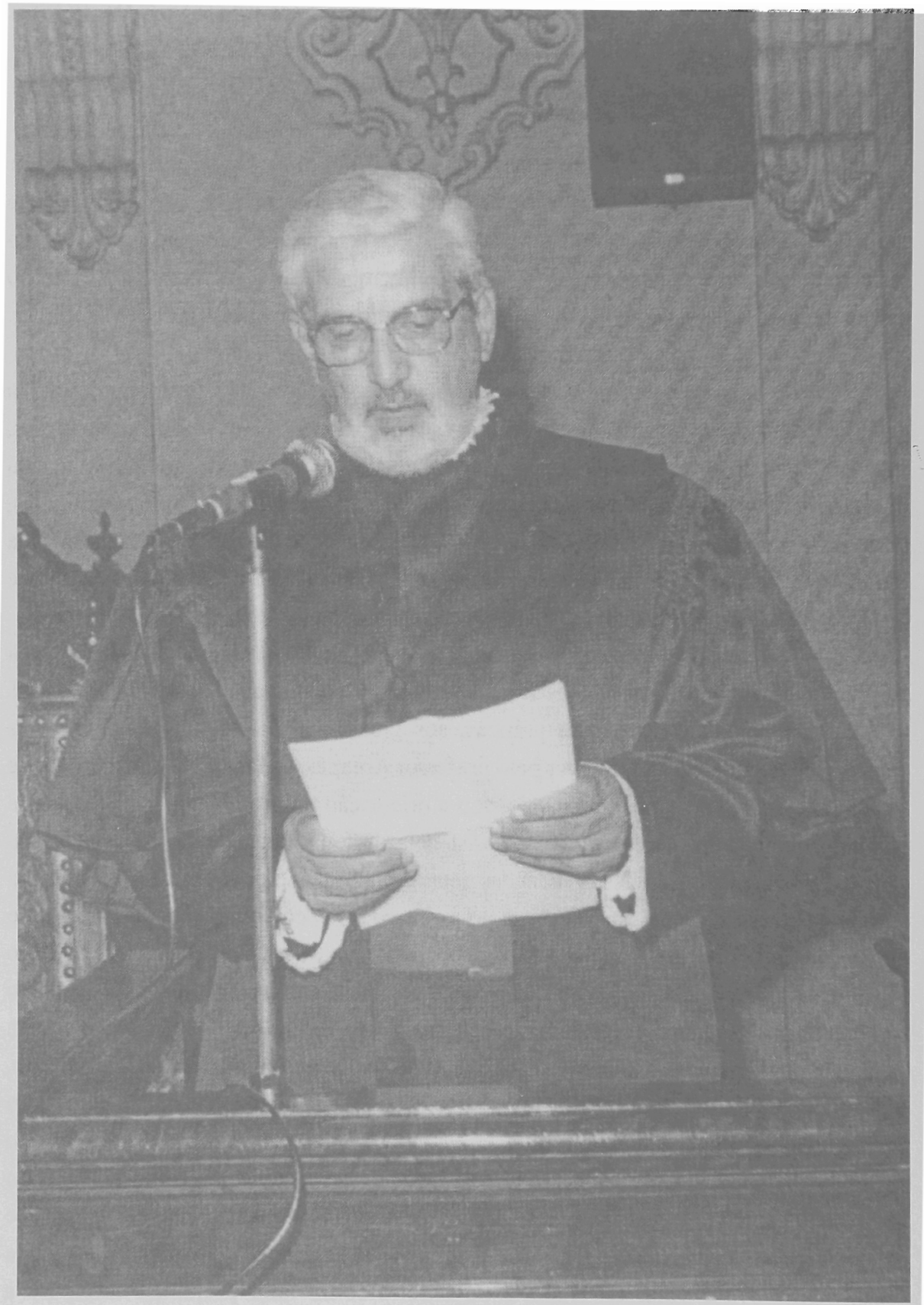

Professor Doutor Luiz Carlos de Azevedo 
compreensão e entendimento das instituições vigentes. Sucedeul-o o professor João Pedro da Veiga Filho, até que, ao sobrevir a reforma do ensino, em 1901, suprimiu-se a disciplina; e não obstante ponderadas e reiteradas manifestações para que retornasse ao curso, a exemplo do que ocorria e ocorre nas mais tradicionais universidades européias, onde o estudo da História do Direito é imprescindivel e obrigatório, somente em 1990 veio ela reincorporar-se ao elenco das disciplinas, desenvolvendo-se, hoje, no terceiro e quarto semestres do curso de graduação; situa-se no Departamento de Direito Civil, tendo sido o seu primeiro professor, nesta fase, o professor Antonio Junqueira de Azevedo; e, agora, por este que vos dirige a palavra e pelo professor Ignácio Maria Poveda Velasco.

De sua importância em outro lance já nos referimos, do qual pequeno trecho permitimo-nos relembrar:

"A História do Direito não se reduz a um inventário, nem se limita, apenas, a erguer e revolver os antecedentes históricos das instituições jurídicas; explica-se, não pela volta a antiguidade, mas pelo fato de constituir o único caminho para a compreensão da essência do Direito na sua atual conjuntura.

Na condição de ciência que é, descreve e revela; pesquisa e esclarece; coordena e explicita a vida jurídica de um povo em seus mais variados aspectos, detendose nas fontes, nos costumes, na legislação que o rege, em todas as manifestações, enfim, que possibilitem o aperfeiçoamento dessa compreensão como um todo, resultante do conhecimento dos fatos ocorridos e das impressões maiores ou menores que estes deixaram.

É tanto uma ciência histórica, quanto jurídica; em face desta dualidade, sua área de atuação nạo se restringe a limites rígidos ou previamente direcionados; já que não se conforma com a mera descrição dos fenômenos jurídicos, deve compreendêlos e explicá-los desde o momento em que sucederam, como na seqüência temporal na qual persistiram sobrevivendo ou deixaram de existir.

Não é um trabalho fácil: para bem entender o significado e alcance de um determinado ordenamento de natureza jurídica, o pesquisador desdobra o seu estudo por etapas, dirigindo-se, primeiramente, ao conteúdo das normas e instituições; partirá, depois, para as condições sociais que levaram ao estabelecimento daquelas e destas; competirá perscrutar o problema da efetividade do ordenamento no meio que lhe corresponde, certificando-se de que forma e em que medida tais e quais institutos ainda se encontram válidos, por que desapareceram, ou, ainda, por que não dispõem nem exercem mais a influência que antes gozavam.

Um esforço de tal porte não interessa apenas sob o ponto de vista histórico, 
circunscrito ao retrospecto dos fatos e atos vividos e legados aos pósteros; mas traduz utilidade, também, ao jurista de hoje, prático, técnico, dogmático, pois não é possível desvincular o direito atual das causas que determinaram a sua juridicidade.

Há verdades fundamentais a serem consideradas: por mais que se pretenda afogar o passado, o fundo tradicional sempre emerge, principalmente quando se cuida de uma Ciência como o Direito, a qual, por índole, é mais conservadora do que as outras; e por mais que se removam ou substituam as instituições, nunca se desprezam, por inteiro, aquelas que consolidaram a estrutura básica da sociedade, as quais perduram no tempo e no espaço à conta de inarredável condicionalismo histórico.

Ademais, se alguém aspira dedicar-se seriamente ao estudo do Direito, empregando-o e utilizando-o para o exercício de sua atividade profissional, não pode reduzir-se à leitura sistemática dos textos legais vigentes, aplicando-os mecanicamente na medida em que se possam ajustar aos casos concretos; a tarefa é sobremaneira ingente: compreensão e explicação; sugestões e idéias; experiência e interpretação, são qualidades que se integram a este trabalho; e no qual se insere, por sua vez, a História do Direito, pois ela ensina que o Direito não surgiu espontaneamente do nada, mas sempre esteve condicionado a incontáveis ordens de realidade, nunca estáticas, mas dinâmicas, e que se alternam conforme igualmente se modificam outros inumeráveis fatores que a vida continuadamente proporciona".

Tais reflexões melhor se exemplificam, todavia, quando comparamos as normas que o direito positivo fornece à sociedade, na seqüência dos anos e dos séculos: algumas, por sua clareza e objetividade, naturalmente permanecem, assim como acontece com as regras do Digesto, e que se repetem em nosso Código Civil, possibilitando o fácil entendimento de quem as lê, e sem dificuldade as compreende; enquanto outras, porque mal seguras na origem e na exposição, pouco duram, são desprezadas, acabam substituídas; é o que se observa no enxurro das ditas medidas provisórias, - que nem medidas são, porque medidas têm limites, e elas não; e que, ao contrário do que dizem, prolongam-se no tempo, aguardando as disposições definitivas, lerdas no chegar; e que, quando chegam, trazem os mesmos vícios e as mesmas dificuldades no entendimento, parecendo que o legislador teve a intenção propositada de torná-la intricada e dificil, capaz de fazer inveja aos rebuscados e tormentosos trechos das três Ordenações do Reino.

Mas não é este um momento para crítica, muito ao contrário, traduz-se na alegria, congraçamento, e agradecimento; alegria pelo conhecimento que se pretendeu haurir, obstinadamente, nestes dias, meses e anos de persistente estudo, na convivência 
contínua dos ideais do Direito; alegria, pelas tarefas que a Divina Providência levou-nos a executar, desde os longínquos tempos da advocacia; junto aos companheiros do Instituto dos Advogados de São Paulo e da Seccional de São Paulo, da Ordem dos Advogados do Brasil; com os juízes do Primeiro Tribunal de Alçada de São Paulo e desembargadores do Tribunal de Justiça de São Paulo, com os quais muito apreendemos, no período em que nos foi dada a dificil, mas gratificante missão de distribuir e aplicar a Justiça; com os companheiros do ensino superior particular, em instituição que, modestamente iniciada em 1967, transformou-se no Unifieo, centro universitário que reúne, hoje, mais de vinte cursos superiores, ministrados para cerca de doze mil alunos; e de congraçamento, com os amigos e colegas desde os bancos escolares e acadêmicos; com os nossos mestres de sempre; com a Senhora Diretora, professora Ivette Senise Ferreira, que tão bem dirige os destinos desta tradicional instituição; com os professores da casa e de outras entidades a quem nos foi dada a honra de lecionar; com centenas e centenas de alunos que hoje se encontram desempenhando com esmero e dedicação suas tarefas profissionais; e, por último, e em especial, com a nossa família, esposa, filhos, nora, netos, principal razão de ser de toda esta empreitada. A Ana Maria, Luiz Carlos, Maria Regina, Maria Cristina, Maria Carolina, Regina Helena e aos sete netos, nosso agradecido abraço.

É, enfim, todo um cabedal que se conserva com redobrado afinco, e que nos faz sentir tão jovens como na época em que com o Professor Fábio Nusdeo subíamos as escadarias do Colégio São Luís. Deve ele se lembrar do soneto que tínhamos de decorar nas aulas de literatura, "Contrastes", do padre Antonio Thomaz, exímio poeta, tanto nas idéias, que colocava, quanto nos decassílabos, que construía; referia-se ele, às "esperanças que seguiam à frente, quando partíamos, no vigor dos anos, rindo e cantando, despreocupadamente; as quais, de repente, quando menos se podia prever, acabavam ficando para trás, rendidas que vinham, pelos desenganos."

Pois bem. Para nós, podemos afirmar, ao cabo de todo este périplo, embora nem sempre tenham sido amenas as surpresas que a vida nos oferece, sentimos que as esperanças continuam à frente, representada por todos estes inestimáveis valores que nos acompanham, incentivam e confortam.

Estamos aqui e agora, então, assim como o João da Ega e mais o Carlos, de Eça de Queiroz: correndo para não perder a condução: tanto aqueles, "pernas abaixo da rampa do Santos", como nós, para alcançar o bonde que fazia o percurso pela Avenida Paulista: "Vamos lá, vamos lá, ainda o apanhamos"! 